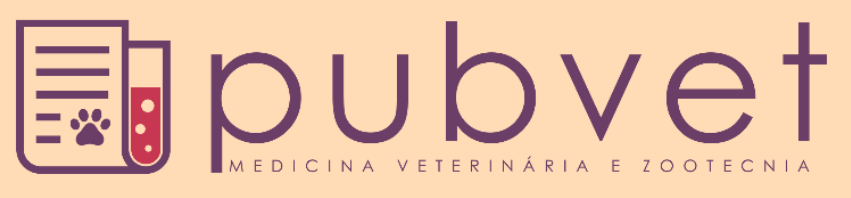

https://doi.org/10.31533/pubvet.v14n10a664.1-8

\title{
Nefrectomia associada à renomegalia direita em um cão acometido por hidronefrose
}

\author{
Talita Wajczyk ${ }^{1 \oplus}$, Rodrigo Von Muhlen² ${ }^{2}$, Janaína Lustosa de Mello ${ }^{3 \oplus}$, Tatiane Furtado de

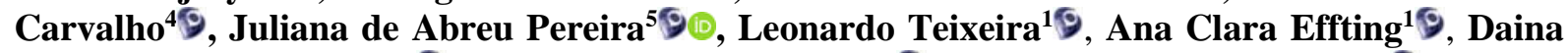 \\ Cristina Nehls Coutinho ${ }^{19}$, Ariele Aparecida Ferreira ${ }^{2} \mathfrak{9}$, William Timboni Teixeira ${ }^{5 *}$ \\ ${ }^{I}$ Discente do curso de Medicina Veterinária da Universidade Sociedade Educacional de Santa Catarina, Campus Joinville. Joinville - SC Brasil. \\ ${ }^{2}$ Médico(a) veterinário autônomo. Joinville - SC Brasil. \\ ${ }^{3}$ Médico(a) veterinário no Centro de Bem Estar Animal de Joinville, Joinville - SC Brasil. \\ ${ }^{4}$ Docente do curso de Medicina Veterinária do Instituto Federal Catarinense, Campus de Araquari, Araquari-SC, Brasil \\ ${ }^{5}$ Docente do curso de Medicina Veterinária da Universidade Sociedade Educacional de Santa Catarina, Campus Joinville. Joinville - SC Brasil. \\ *Autor para correspondência, E-mail:william.teixeira@unisociesc.com.br
}

\begin{abstract}
Resumo. A hidronefrose decorre de obstrução total ou parcial do trato urinário inferior, o que promove dilatação progressiva da pelve renal, e por consequência, compressão e atrofia do parênquima. Embora sua casuística seja baixa, seu diagnóstico é favorecido por exames clínico, laboratoriais e de imagem. O objetivo deste trabalho foi relatar o caso de um cão sem raça definida (SRD) adulto portador de hidronefrose acentuada que culminou com nefrectomia unilateral direita. $\mathrm{O}$ animal apresentava abdome distendido sem resposta dolorosa e uma ferida em flanco pelo qual drenava secreção sanguinopurulenta. Exames laboratoriais indicaram anemia normocítica normocrômica, leucocitose com desvio à esquerda e aumento das proteínas plasmáticas. Durante o ato cirúrgico, o rim direito encontrava-se aderido ao peritônio, baço, pâncreas, omento, fígado e estômago. Não havia líquido livre abdominal ou sinais de inflamação peritoneal e/ou retroperitoneal. Perda do parênquima renal com substituição por tecido conjuntivo fibroso intenso foi verificado microscopicamente. Neste relato é descrita a evolução deste caso desde sua consulta inicial até os noventa dias após o pós-operatório. A causa base da doença não foi esclarecida.
\end{abstract}

Palavras chave: canino, dilatação, hidronefrose, rim

\section{Nephrectomy associated with right renomegaly in a dog affected by hydronephrosis}

Abstract. Hydronephrosis results from a total or partial obstruction of the lower urinary
Hydronephrosis results from total or partial obstruction of the lower urinary tract, which
promotes progressive dilation of the renal pelvis, and consequently, compression and
atrophy of the parenchyma. Although its casuistry is low, its diagnosis is favored by
clinical, laboratory and imaging exams. The aim of this study was to report the case of an
adult mixed breed (SRD) dog with severe hydronephrosis that culminated in unilateral right
nephrectomy. The animal had a distended abdomen with no painful response and a flank
wound through which it drained blood and purulent secretion. Laboratory tests indicated
normochromic normocytic anemia, leukocytosis with deviation to the left and increased
plasma proteins. During the surgery, the right kidney was attached to the peritoneum,
spleen, pancreas, omentum, liver and stomach. There were no free abdominal fluids or
signs of peritoneal and / or retroperitoneal inflammation. Loss of renal parenchyma with
replacement by intense fibrous connective tissue was verified microscopically. This report 
describes the evolution of this case from its initial consultation to the ninety days after the postoperative period. The underlying cause of the disease has not been clarified.

Keywords: canine, dilation, hydronephrosis, kidney

\section{Nefrectomía asociada con renomegalia derecha en un perro afectado por hidronefrosis}

Resumen. La hidronefrosis es el resultado de una obstrucción total o parcial del tracto urinario inferior, que promueve la dilatación progresiva de la pelvis renal y, en consecuencia, la compresión y la atrofia del parénquima. Aunque su casuística es baja, su diagnóstico se ve favorecido por los exámenes clínicos, de laboratorio y de imágenes. El objetivo de este estudio fue informar el caso de un perro adulto mestizo con hidronefrosis severa que culminó en nefrectomía derecha unilateral. El animal tenía el abdomen distendido sin respuesta dolorosa y una herida en el costado a través de la cual drenaba la secreción sangrienta y purulenta. Las pruebas de laboratorio indicaron anemia normocrómica normocítica, leucocitosis con un desplazamiento a la izquierda y un aumento de las proteínas plasmáticas. Durante la cirugía, el riñón derecho se unió al peritoneo, el bazo, el páncreas, el epiplón, el hígado y el estómago. No hubo fluidos abdominales libres ni signos de inflamación peritoneal y / o retroperitoneal. La pérdida del parénquima renal con reemplazo por tejido conectivo fibroso intenso se verificó microscópicamente. Este informe describe la evolución de este caso desde su consulta inicial hasta los noventa días posteriores al postoperatorio. La causa subyacente de la enfermedad no se fue aclarada.

Palabras clave: canino, dilatación, hidronefrosis, riñón

\section{Introdução}

A hidronefrose decorre de obstrução total ou parcial do trato urinário inferior, o que promove dilatação progressiva da pelve renal e, por consequência, compressão e atrofia do parênquima renal (Şahal et al., 2005). As causas de obstruções são variadas, a citar: urolitíases, ureter ectópico, trauma, hérnia perineal, pielonefrite recorrente e complicações cirúrgicas (Choi et al., 2010; Vaidyanathan et al., 2012), neoplasias na uretra e próstata, obstrução por inflamação no trato urinário inferior, massas extrínsecas e ligadura cirúrgica acidental de ureter (Dibartola \& Westropp, 2015; Kealy, 2012; Vac, 2004).

A idade média de manifestação dessa doença é de nove anos e não há predileção por sexo ou raça (Choi et al., 2010). De acordo com o estudo de Inkelmann et al. (2012), 9,3\% das lesões do sistema urinário estão relacionadas à pelve renal $(\mathrm{n}=1063)$, sendo a hidronefrose constatada em 3,85\% dos casos.

Nos animais cuja evolução da doença é lenta e progressiva, os sinais clínicos podem não ser observados inicialmente (Rousset et al., 2011). Os pacientes acometidos comumente apresentam quadro de azotemia e falência renal (Silveira et al., 2008).

No exame ultrassonográfico são observados conteúdo anecóico no interior do sistema coletor de urina e ausência de evidências de peritonite (Choi et al., 2010). A pionefrose é o principal diagnóstico diferencial, sendo seu aspecto sonográfico hiperecóico. Essa afecção é a evolução de um quadro de pielonefrite ou hidronefrose com infecção ascendente (Choi et al., 2010).

É essencial para a confirmação do diagnóstico; e também do prognóstico, deliberar se a obstrução é uni ou bilateral; além de examinar o trajeto do ureter à vesícula urinária para identificação da causa da hidronefrose. $\mathrm{O}$ tratamento conservador visa restabelecer o fluxo urinário, diagnosticando a causa da hidronefrose (Silveira et al., 2008), sendo a nefrectomia indicada para os estágios avançados (Santarosa et al., 2007) quando a morfologia do órgão é afetada, gerando saculação repleta de líquido (Slatter, 1998). 
O objetivo deste trabalho foi relatar um caso incomum de paciente com abdome distendido encaminhado para laparotomia exploratória. O quadro cursou com nefrectomia do rim direito, o qual pesou três quilos e foi acometido por hidronefrose de origem não esclarecida.

\section{Relato de caso}

Foi atendido pelo Centro de Bem-Estar Animal de Joinville um cão sem raça definida (SRD), errante, sem histórico conhecido, macho, não castrado, adulto e pesando catorze quilos. $\mathrm{O}$ animal foi acolhido por um munícipe após invadir sua residência e relatou que o cão não defecava. A queixa principal do resgatante foi a presença de lesão ulcerativa na região do flanco direito e prurido intenso nas regiões abdominal e inguinal.

Ao exame físico o animal apresentava temperatura retal de $39{ }^{\circ} \mathrm{C}$, tempo de preenchimento capilar de $2 \mathrm{~s}$, frequências cardíacas de $100 \mathrm{bpm}$ e respiratória de $30 \mathrm{mpm}$, mucosas normocoradas, baixo escore corporal e orifício na região do flanco direito medindo $1,0 \times 1,0 \mathrm{~cm}$ pelo qual drenava secreção sanguinopurulenta. A pele era eritematosa nas regiões abdominal e inguinal. $\mathrm{O}$ abdome encontrava-se intensamente distendido (Figura 1) e sem resposta dolorosa. Foi iniciada terapia para as lesões cutâneas utilizando cefalexina ( $6 \mathrm{mg} / \mathrm{kg}$ em cápsula, BID por 10 dias), anti-histamínico a base de clemastina $(0,07$ $\mathrm{mg} / \mathrm{kg}$ em comprimido, SID por 10 dias), meloxicam $(0,1 \mathrm{mg} / \mathrm{kg}$ em comprimido SID por 4 dias) e unguento tópico na região do ferimento do flanco associado a uso de colar Elisabetano.
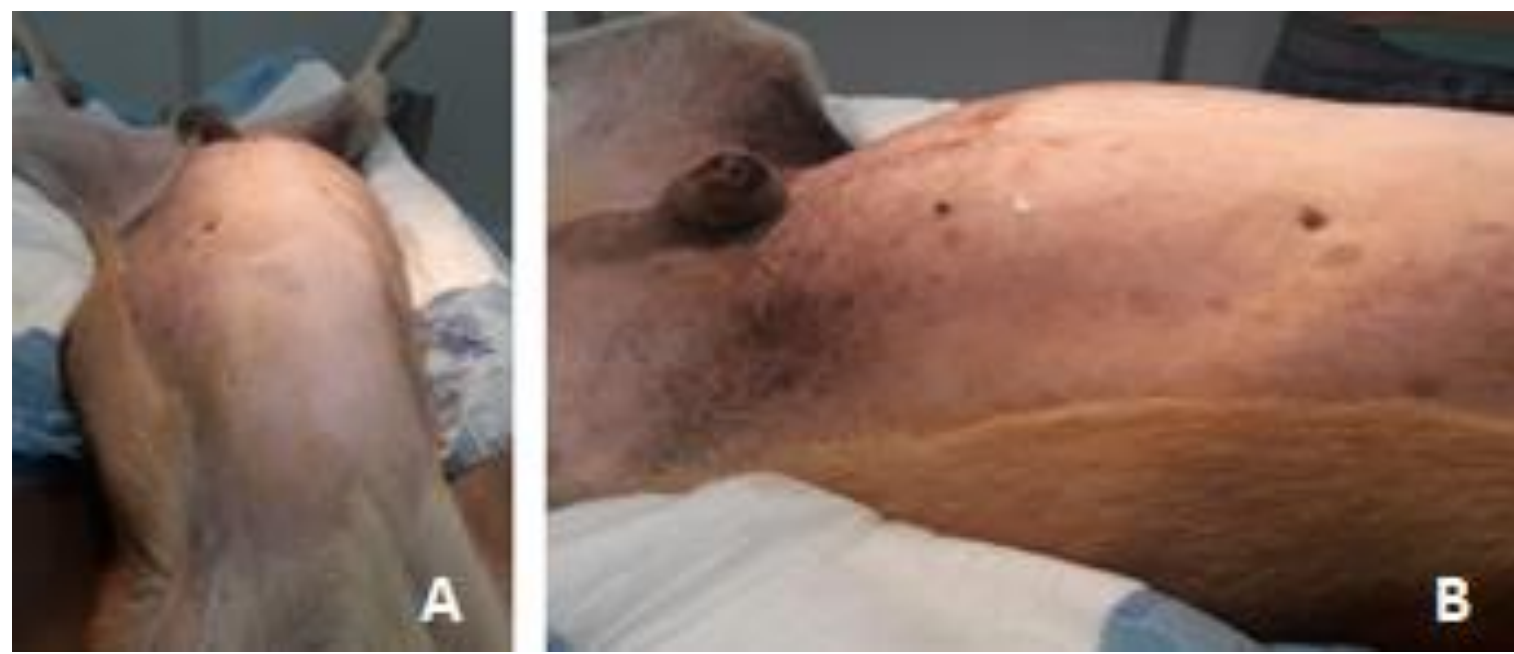

Figura 1. Aumento de volume abdominal direito no sentido (A) crânio-caudal e (B) latero-lateral de um cão macho, adulto.

Após dez dias do início do tratamento, o paciente retornou sem melhora da lesão cutânea no flanco e o abdome permanecia distendido. Diante da pobre resposta ao tratamento, exames complementares foram solicitados. O hemograma (Tabela 1, coluna Resultado no $1^{\circ}$ Retorno) indicou aumento das proteínas plasmáticas totais, anemia normocítica normocrômica, eritrócitos com discreta policromasia e trombocitose. No leucograma (Tabela 2 , coluna Resultado no $1^{\circ}$ Retorno) observou-se leucocitose com neutrofilia, desvio à esquerda regenerativo e monocitose. O resultado para pesquisa por hemoparasitos foi negativo. Os exames bioquímicos (Tabela 3 , coluna Resultado no $1^{\circ}$ Retorno) não evidenciaram alterações. Diante disso, optou-se por alterar o antibiótico para amoxicilina com clavulanato de potássio em cápsulas ( $25 \mathrm{mg} / \mathrm{kg} \mathrm{VO}$, BID por 10 dias) de maior espectro.

Ao ultrassom verificou-se a presença de estrutura na região inguinal direita que impossibilitou a visualização dos órgãos da cavidade abdominal. Optou-se por laparotomia exploratória para diagnóstico e remoção da estrutura. Foram administrados como medicação pré-anestésica cetamina $(6 \mathrm{mg} / \mathrm{kg})$ e midazolam $(0,5 \mathrm{mg} / \mathrm{kg})$ por via endovenosa $(\mathrm{EV})$; e metadona $(0,3 \mathrm{mg} / \mathrm{kg})$ por via intramuscular. A indução da anestesia foi proporcionada pelo uso de propofol (4 $\mathrm{mg} / \mathrm{kg})$ e a manutenção realizada com o isoflurano.

Após incisão por celiotomia mediana, iniciou-se exploração da cavidade abdominal onde foi palpada grande estrutura de conteúdo líquido que ocupava ambos lados da cavidade. Encontrava-se ainda 
fortemente aderida ao peritônio lateral direito, coberta por vasos calibrosos e omento, o que dificultava sua exposição (Figura $2 \mathrm{~A})$.

Tabela 1. Resultados dos exames de eritrograma realizados em um cão adulto, macho ${ }^{1}$.

\begin{tabular}{lcccc}
\hline Parâmetro & $\begin{array}{c}\text { Resultado no } 1^{\circ} \\
\text { Retorno }\end{array}$ & $\begin{array}{c}\text { Resultado no } 2^{\circ} \\
\text { Retorno }\end{array}$ & $\begin{array}{c}\text { Resultado após 3 meses de } \\
\text { cirurgia }\end{array}$ & Referência \\
\hline Eritrócitos & 2,45 & 3,85 & 7,38 & $5,50-8,50{\mathrm{milhões} / \mathrm{mm}^{3}}^{\text {Hematócrito }}$ \\
Hemoglobina & 5,0 & 23 & 42 & $37-55 \%$ \\
VCM & 69,5 & 7,6 & 14,5 & $12-18 \mathrm{~g} / \mathrm{dL}$ \\
CHCM & 32,3 & 59,74 & 56,91 & $60-77 \mathrm{fL}$ \\
Proteínas Plasmáticas Totais & 9,0 & 33,0 & 34,5 & $30-36 \%$ \\
RWD & 14,7 & 7,20 & 8,2 & $5,5-8,0 \mathrm{~g} / \mathrm{dL}$ \\
Plaquetas & 654 & 17,8 & 16 & $12-16 \%$ \\
\hline
\end{tabular}

${ }^{1}$ Método automatizado utilizando Equipamento URIT 3000 VET, com observação microscópica de esfregaço em lâmina.

Os vasos maiores foram ligados com fio monofilamentar não absorvível (Sertix; Shalon Suturas) e os menores, cauterizados com bisturi bipolar (Bmo-870; Medcir). Foi realizada divulsão manual da região aderida ao peritônio e o omento que recobria a estrutura foi removido. As aderências localizadas abaixo da estrutura se estendiam à região vertebral, estômago, pâncreas (Figura 2B) e baço. Devido à perda sanguínea foi realizada transfusão transoperatória de $250 \mathrm{~mL}$ de sangue total.

Tabela 2. Resultados dos exames de leucograma realizados em um cão adulto, machoํ.

\begin{tabular}{lcccc}
\hline Parâmetro & $\begin{array}{c}\text { Resultado no } 1^{\circ} \\
\text { Retorno }\end{array}$ & $\begin{array}{c}\text { Resultado no } 2^{\circ} \\
\text { Retorno }\end{array}$ & $\begin{array}{c}\text { Resultado após 3 meses de } \\
\text { cirurgia }\end{array}$ & Referência/mm ${ }^{3}$ \\
\hline Leucócitos totais & 38.1 & 13.3 & 12.1 & $6.000-17.000$ \\
Metamielócitos & 0 & 0 & 0 & - \\
Bastonetes & 2.286 & 266 & 0 & $0-510$ \\
Segmentados & 27.813 & 4.389 & 8.833 & $3.600-13.100$ \\
Linfócitos & 2.286 & 7.448 & 1.936 & $720-5.100$ \\
Monócitos & 4.572 & 931 & 242 & $180-1.700$ \\
Eosinófilos & 1.143 & 266 & 1.089 & $120-1.700$ \\
Basófilos & 0 & 0 & 0 & $0-170$ \\
\hline
\end{tabular}

${ }^{1}$ Método automatizado utilizando Equipamento URIT 3000 VET com observação microscópica de esfregaço em lâmina.

Constatou-se que a estrutura tratava-se do rim direito do animal. Os vasos renais (Figura 3A), os quais estavam divergentes da posição anatômica habitual, foram identificados e ligados. As ligaduras do ureter direito foram estabelecidas próximo ao hilo renal (Figura 3B) e à vesícula urinária com fio monofilamentar não absorvível 2-0 (Figura 3C), com remoção subsequente do órgão (Figura 3D). O calibre do ureter encontrava-se ligeiramente dilatado, uniforme em sua extensão e sem evidencias de obstrução (Figuras 3B e 3C).

Tabela 3. Resultados dos exames de bioquímica sérica realizados em um cão adulto, macho ${ }^{1}$.

\begin{tabular}{lcccc}
\hline Parâmetro & $\begin{array}{c}\text { Resultado no } 1^{\circ} \\
\text { Retorno }\end{array}$ & $\begin{array}{c}\text { Resultado no } 2^{\circ} \\
\text { Retorno }\end{array}$ & $\begin{array}{c}\text { Resultado após 3 meses de } \\
\text { cirurgia }\end{array}$ & Referência \\
\hline ALT & 14,0 & 19,2 & 88,3 & $10-102 \mathrm{U} / \mathrm{L}$ \\
AST & 22,1 & 53,6 & - & $10-80 \mathrm{U} / \mathrm{L}$ \\
Creatinina & 0,79 & 1,14 & 1,15 & $0,4-1,8 \mathrm{mg} / \mathrm{dL}$ \\
FA & 143,8 & 54,4 & 39,6 & $20-150 \mathrm{U} / \mathrm{L}$ \\
Uréia & 37,7 & 65,0 & 50,1 & $15-65 \mathrm{mg} / \mathrm{dL}$ \\
\hline
\end{tabular}

${ }^{1}$ Método cinético no equipamento RESPONS 910. 
$\mathrm{Na}$ avaliação macroscópica do rim esquerdo, observou-se que seu tamanho era compatível com o porte do animal, não havia líquido livre abdominal ou sinal de inflamação peritoneal e/ou retroperitoneal. $\mathrm{O}$ fechamento da cavidade abdominal ocorreu de forma rotineira conforme Fossum (2014). Após o término do procedimento cirúrgico o rim direito foi pesado e o resultado desta avaliação indicou o peso de três quilos.
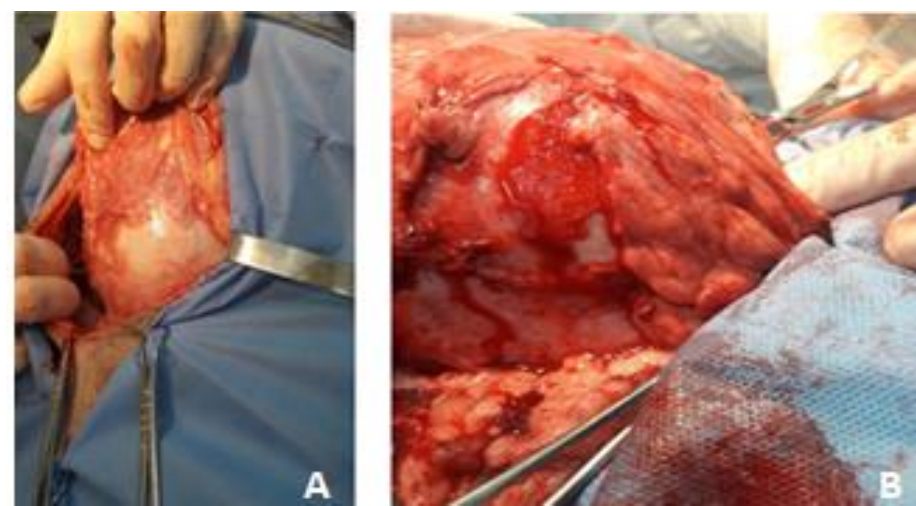

Figura 2. Laparotomia exploratória em cão adulto, macho, na qual se observa: (A) o acesso a cavidade abdominal com tentativa de exposição do rim direito na região abdominal, (B) aderência do pâncreas ao rim direito na porção cranial.
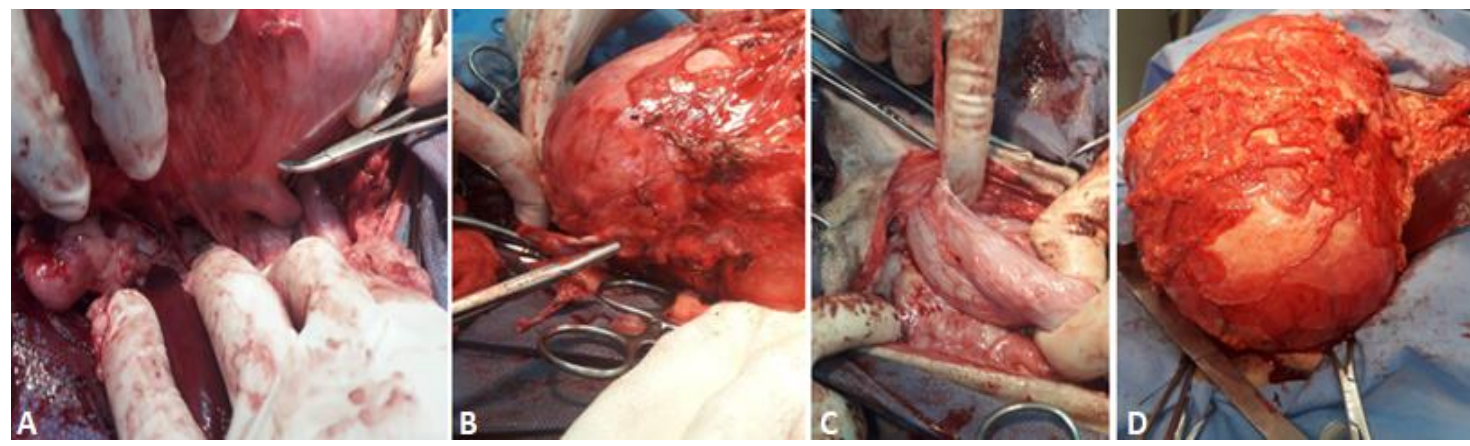

Figura 3. Detalhes da nefrectomia do rim direito em cão adulto, macho: (A) acesso aos vasos renais calibrosos do rim direito, $(\mathbf{B})$ ureter próximo ao hilo renal, $(\mathbf{C})$ ligadura do ureter próximo à vesícula urinária, e (D) exposição total do órgão imediatamente antes de sua remoção.

O paciente recebeu no pós-operatório imediato por via endovenosa ceftriaxona ( $25 \mathrm{mg} / \mathrm{kg} \mathrm{BID})$, dipirona (25 mg/kg BID) e meloxican $(0,1 \mathrm{mg} / \mathrm{kg}$ SID). Manteve boa recuperação e foi liberado para casa do munícipe no dia seguinte com prescrição por 5 dias a ser administrado por via oral metronidazol ( $25 \mathrm{mg} / \mathrm{kg}$ BID), sulfadimetoxina (27,5 mg BID) e enrofloxacina ( $5 \mathrm{mg} / \mathrm{kg} \mathrm{SID})$. Foram ainda prescritos, administrados por mesma via, tramadol (4 mg/ $/ \mathrm{kg}$ em cápsulas BID por 7 dias), meloxican $(0,1 \mathrm{mg} / \mathrm{kg}$ em comprimidos SID por 4 dias) e dipirona ( $25 \mathrm{mg} / \mathrm{kg}$ BID por 15 dias).
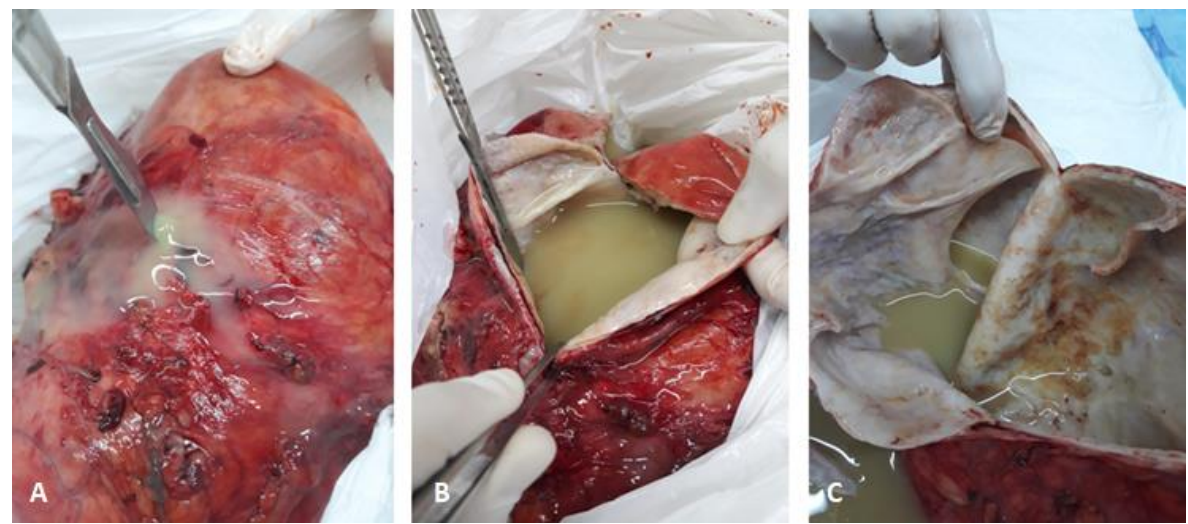

Figura 4. Imagens do rim direito removido em cão adulto, macho em uma laparotomia exploratória: (A) aspecto do rim direito após nefrectomia e imediatamente após incisão para verificação de conteúdo interno, (B) detalhe do líquido de coloração amarelo-esverdeado no interior do órgão, e $(\mathbf{C})$ tecido remanescente do rim direito. 
$\mathrm{O}$ órgão removido foi submetido à incisão, onde foi observado abundante líquido viscoso de coloração amarelo-esverdeado, conforme Figuras 4A, 4B e 4C. Amostra do tecido renal foi coletada e armazenada em formol 10\% para avaliação histopatológica. A análise microscópica revelou difusa substituição do parênquima renal por tecido conjuntivo fibroso (Figura 5A) associado a numerosos vasos sanguíneos (Figura 5B) ectásicos e infiltrado inflamatório linfo-plasmocitário multifocal moderado no interstício e adjacente ao epitélio da pelve renal. Os achados histológicos são compatíveis com processo degenerativo crônico.
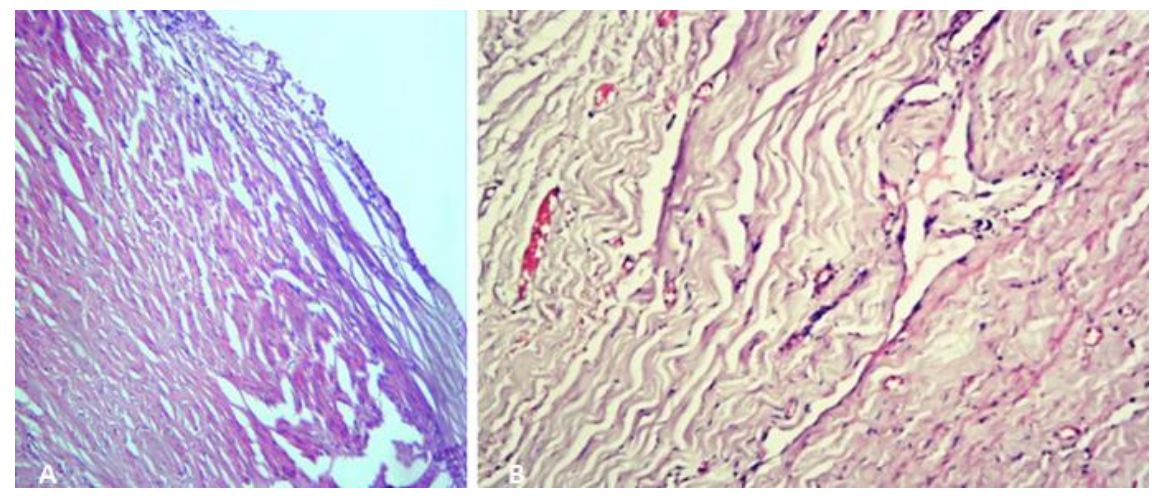

Figura 5. Microscopia de rim de um cão adulto, macho que apresentava proliferação de tecido conjuntivo fibroso (A) e proliferação de vasos sanguíneos (B). Hematoxilina e eosina, aumento de 100x.

Após o tratamento cirúrgico, o paciente retornou apresentando bom estado geral, porém em quadro anêmico com discreta anisocitose e linfocitose com morfologia celular normal (Tabelas 1, $\underline{2}$ e $\underline{3}$, coluna Resultado no $2^{\circ}$ Retorno). Três meses após a nefrectomia, o paciente encontrava-se com escore corporal adequado (Figura 6A) e cicatrização completa da ferida no flanco direito (Figura 6B) por segunda intenção. $\mathrm{O}$ quadro anêmico e a linfocitose foram corrigidos, os parâmetros da bioquímica sérica (Tabelas 2 e $\underline{3}$, coluna Resultado após 3 meses de cirurgia, respectivamente) permaneceram dentro da normalidade, enquanto valor de proteína plasmática total estava discretamente acima do valor de referência (Tabela 1). Após um ano da realização da nefrectomia o paciente encontra-se vivo.
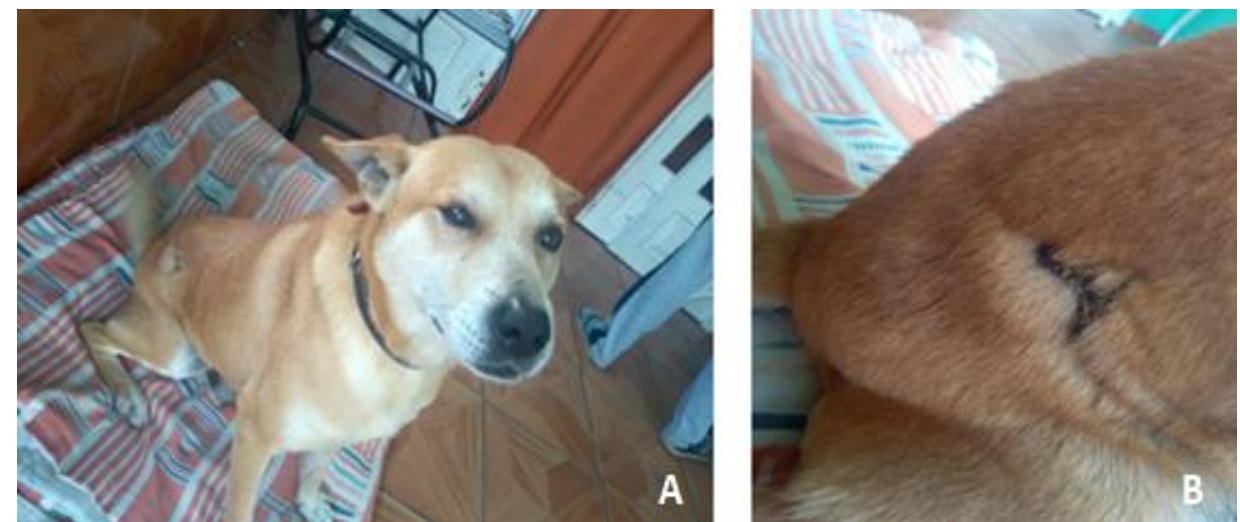

Figura 6. Foto de acompanhamento do paciente após três meses da cirurgia de laparotomia exploratória (A) aspecto geral do paciente e $(\mathbf{B})$ detalhe da cicatrização da ferida no flanco direito por segunda intenção.

\section{Discussão}

Ao se inspecionar a renomegalia direita repleta de conteúdo líquido era esperado encontrar obstrução no trato urinário capaz de promover o acúmulo de líquido no rim, característico da fisiopatologia de hidronefrose e pionefrose (Choi et al., 2010; Vaidyanathan et al., 2012). Entretanto, nada foi observado macroscopicamente, não sendo observadas massas, urólitos, sinais de trauma ou cirurgia prévia.

A obstrução causada por um rim mal posicionado congenitamente com dobramento secundário do ureter como mencionado por Newman et al. (2011) poderia ser uma das causas de base desta afecção, visto que no transcirúrgico foi constatado que os vasos não se encontravam em posição anatômica habitual. Todavia, o peso e a dimensão do rim do paciente deste relato promoveriam deslocamento 
relativo do órgão, o que não permitiria afirmar se havia alteração congênita prévia de posicionamento. A hidronefrose foi associada à traumas e obstrução do fluxo urinário oriunda da formação de coágulos (Ames et al., 2005; Raposo et al., 2013), mas de mínima incidência.

Os achados laboratoriais (leucocitose, trombocitopenia e neutrofilia), anatomo-histopatológicos (relativos à presença de tecido fibroso, ausência de tecido renal e conteúdo líquido viscoso de coloração amarelo-esverdeado no interior do órgão) e sinais clínicos (abaolamento do abdome) sugerem o diagnóstico de hidronefrose. Assim como reportado por Raposo et al. (2013) em um caso de hidronefrose em cão, observou-se leucocitose com desvio à esquerda com aumento da proteína plasmática total e funções hepáticas e renais normais no diagnóstico desta afecção.

Em estágios avançados, o rim hidronefrótico é descrito por Newman et al. (2011) como um saco de parede fina ( 2 a $3 \mathrm{~mm}$ de espessura) preenchido por fluido, o que dificulta sua manipulação devido a fragilidade e possibilidade de ruptura; podendo encontrar-se contaminado por bactérias e estar preenchido por pus, no caso da pionefrose.

Conforme o exame macroscópico há formação de uma bolsa a partir da cápsula renal com o desaparecimento visual do parênquima do rim direito, evidenciado nos achados histopatológicos. Tipicamente essa bolsa é formada pela pressão exercida no tecido renal pelo líquido contido na pelve do órgão, comprometendo a sua integridade e causando atrofia compressiva do parênquima (Newman et al., 2011).

Vaidyanathan et al. (2012) e Santarosa et al. (2007) relatam ainda o uso do ultrassom como ferramenta para o diagnóstico dessa patologia, descrevendo as características morfológicas e de ecogenicidade. Ressalta-se, todavia, que o diagnóstico poderia ser realizado por técnicas de radiografia para avaliação de urólitos, pielografia anterógrada (Raposo et al., 2013) ou por urografia excretora para verificação de anomalias em pelve e ureter (Slatter, 1998). Essas técnicas elucidariam o diagnóstico e contribuiriam no planejamento cirúrgico.

A nefrectomia foi indicada considerando o estado do rim observado no transcirúrgico, suas aderências aos órgãos da cavidade, valores normais relativos à função renal e com possibilidade futura de ruptura. Após a cirurgia, os valores de creatinina e ureia estavam dentro dos valores de referência mesmo após noventa dias do ato cirúrgico, em alinhamento com Raposo et al. (2013).

No tratamento inicial da leucocitose poderia ter sido empregada a amoxicilina com clavulanato de potássio como primeira opção, tendo em vista o amplo espectro de atuação deste antibiótico quando comparado à cefalexina. A troca de antibiótico mostrou-se eficaz ao se observar a contagem total de leucócitos no segundo retorno (Tabela 2 , coluna Resultado no $2^{\circ}$ Retorno). A trombocitose observada pode ocorrer como mecanismo reacional frente a doenças e alterações no funcionamento do organismo, a citar doenças endócrinas, traumas, deficiência de ferro, processos inflamatórios e hemorragia aguda (Rocha et al., 2019). As duas últimas causas são sugestivas para o quadro do paciente no primeiro retorno (Tabela 1, coluna Resultado no $1^{\circ}$ Retorno).

\section{Conclusão}

A evolução da hidronefrose compromete a viabilidade do tecido renal, impacta a fisiologia do trato genitourinário e, portanto, gera prejuízo à qualidade de vida do animal e, consequentemente, leva à óbito. Inúmeras causas originam tal patologia e o diagnóstico precoce via hemograma, bioquímica sérica e exames de imagens proporciona um tratamento correto e um planejamento cirúrgico adequado. Como disposto neste relato, a nefrectomia apresentou desfecho positivo do caso.

\section{Referências bibliográficas}

Ames, C. D., Vanlangendonck, R., Morrissey, K., Venkatesh, R., \& Landman, J. (2005). Evaluation of surgical models for renal collecting system closure during laparoscopic partial nephrectomy. Urology, 66(2), 451-454. https://doi.org/10.1016/j.urology.2005.03.033

Choi, J., Jang, J., Choi, H., Kim, H., \& Yoon, J. (2010). Ultrasonographic features of pyonephrosis in dogs. Veterinary Radiology \& Ultrasound, 51(5), 548-553. https://doi.org/10.1111/j.1740$\underline{8261.2010 .01702 . \mathrm{X}}$ 
Dibartola, S. P., \& Westropp, J. L. (2015). Manifestações clínicas das doenças do trato urinário. In Nelson, R. W., Couto, C. G. Medicina Interna de Pequenos Animais. 5 ed. Rio de Janeiro: Elsevier (pp. 629-652).

Fossum, T. W. (2014). Cirurgia de pequenos animais (4th ed., Vol. 1). Elsevier Brasil.

Inkelmann, M. A., Kommers, G. D., Trost, M. E., Barros, C. S. L., Fighera, R. A., Irigoyen, L. F., \& Silveira, I. P. (2012). Lesões do sistema urinário em 1.063 cães. Pesquisa Veterinária Brasileira, 32(8), 761-771. https://doi.org/10.1590/S0100-736X2012000800015

Kealy, J. K. (2012). O abdomen. In Kealy, J. K., Mcallister, H., Graham, J. P. Radiologia e Ultrassonografia do Cão e do Gato. (Vol. 1, pp. 23-198). Rio de Janeeiro: Elsevier Brasil.

Newman, S. J., Confer, A. W., \& Panciera, R. J. (2011). O sistema urinário. In Zachary, J. F.; Mcgavin, M. D. Bases da Patologia em Veterinária. 4. ed. São Paulo: Elsevier,.

Raposo, T. M. M., Varallo, G. R., Huppes, R. R., Brum, A. M., \& Nardi, A. B. (2013). Dog with hydronephrosis due to abdominal trauma. Pakistan Veterinary Journal. Faisalabad: Univ Agriculture, v. 33, n. 4, p. 526-528, 2013.

Rocha, M. N. A., Rocha, M. C. S., Kavasaki, M. L., Rodrigues, J. Y., Souza, W. F., \& Mendonça, A. J. (2019). Thrombocytosis: a retrospective study of 573 dogs (2016-2017). Ciência Animal Brasileira, 20. https://doi.org/10.1590/1089-6891v20e-51837

Rousset, N., Abbondati, E., Posch, B., Owen, L. J., \& Herrtage, M. (2011). Unilateral hydronephrosis and hydroureter secondary to ureteric atresia, and uterus unicornis in a young terrier. Journal of Small Animal Practice, 52(8), 441-444. https://doi.org/10.1111/j.1748-5827.2011.01084.x

Şahal, M., Haziroğlu, R., Özkanlar, Y., \& Beyaz, L. (2005). Bilateral hydronephrosis and hydroureter in a German shpherd dog. Ankara Üniv Vet Fak Derg.

Santarosa, I. A. M., Godoy, C. L. B., Pippi, N. L., Antunes, P. S. P., Rappeti, J. C. S., Krolikowski, G., Novosad, D., \& Gheller, V. S. (2007). Nefrostomia percutânea ecoguiada em cães. Ciência Rural, 37(3), 762-768. https://doi.org/10.1590/S0103-84782007000300025

Silveira, T., Leite, C. A. L., Feliciano, M. A. R., Sampaio, G. R., \& Alves, E. G. L. (2008). Hidronefrose unilateral associada à dermatopatia em uma cadela - Relato de caso. Nosso Clínico, 64, 12-14.

Slatter, D. H. (1998). Manual de cirurgia de pequenos animais. v.2, cap.104, p.1698-1713. São Paulo: Manole.

Vac, M. H. (2004). Sistema urinário: rins, ureteres, bexiga urinária e uretra. CARVALHO, CF UltraSonografia Em Pequenos Animais. São Paulo: Roca, 111-146.

Vaidyanathan, S., Selmi, F., Abraham, K., Hughes, P., Singh, G., \& Soni, B. (2012). Hydronephrosis and renal failure following inadequate management of neuropathic bladder in a patient with spinal cord injury: Case report of a preventable complication. Patient Safety in Surgery, 6(1), 22. https://doi.org/10.1186/1754-9493-6-22

Recebido: 1 de julho, 2020 .

Aprovado: 4 de agosto, 2020

Disponível online: 8 de outubro, 2020.
Licenciamento: Este artigo é publicado na modalidade Acesso Aberto sob a licença Creative Commons Atribuição 4.0 (CC-BY 4.0), a qual permite uso irrestrito, distribuição, reprodução em qualquer meio, desde que o autor e a fonte sejam devidamente creditados. 